\title{
Gastro-Intestinal Symptoms and Autism Spectrum Disorder: A Potential Link [Letter]
}

\author{
Syeda Lamiya Mir' \\ Abdul Moiz Sahito' \\ Irfan Ullah $\mathbb{D}^{2}$ \\ 'Dow Medical College, Dow University \\ of Health Sciences, Karachi, Pakistan; \\ ${ }^{2}$ Kabir Medical College, Gandhara \\ University, Peshawar, Pakistan
}

Correspondence: Syeda Lamiya Mir Dow Medical College, Dow University of Health Sciences, Karachi, Pakistan

Email lamiyamir@gmail.com

\section{Dear editor}

Moudgal et al published an article in Clinical and Experimental Gastroenterology titled "Systemic Disease Associations with Disorders of Gut-Brain Interaction and Gastrointestinal Transit: A Review". ${ }^{1}$ We want to express our gratitude to the authors for publishing such a thorough review study and would like to make some suggestions.

The paper discussed a variety of multisystem illnesses and their pathophysiological links to disorders of gut brain interface (DGBI) and gastrointestinal motor dysfunction, presenting gastroenterologists with a foundation for differential diagnosis. ${ }^{1}$

Although the article mentioned most of the systemic disorders, we noticed the lack of the overlap of GI symptoms and autism spectrum disorder (ASD) core symptoms.

Autism spectrum disorder (ASD) is a complex neurodevelopmental disorder which manifests as variable phenotypes with different subendo-phenotypes that may represent GI abnormalities. A meta-analysis carried out in 2014 by McElhanon et al, showed that children with ASD, unlike the comparison groups, expressed significantly more general GI symptoms: diarrhea, abdominal pain, and constipation. ${ }^{2}$ Recent studies have shown the shared pathogenic factors and pathophysiological mechanisms revealing the possible link between GI and ASD disturbances, including inflammation of intestine with or without autoimmunity, visceral hypersensitivity with functional abdominal pain and autonomic dysfunction with GI reflux and dysmotility. Absent or slow acquirement of bowel training secondary to trouble with sensory processing and motor problems may lead to altered GI motility and defecation physiology. ${ }^{3}$ Research carried out by Afzal et al concluded moderate-to-severe constipation in $36 \%$ of children with ASD compared to $9 \%$ in a control population. ${ }^{4}$

The diagnosis of GI disorders in patients with ASD can be very challenging due to the behavioral expressions, thus, doctors recommend using less invasive methods of investigation before hospitalization. ${ }^{5}$

In his research, Wasilewska et al concluded that GI disorders in children with ASD may vary greatly in their nature and localization. Due to the phenotypical representation as comorbidity of ASD and GI disorders, we suggest treating this situation as an "overlap syndrome".

Children with ASD who have GI disease and are experiencing unexplained anxiety, self-injury, sleep deprivation, aggression, and agitation will benefit from this concept. We have made significant progress in our studies of ASD; however, 
more research and systemic research are needed to determine the extent to which GI and ASD are linked.

\section{Disclosure}

The authors report no conflicts of interest for this communication.

\section{References}

1. Moudgal R, Schultz AW, Shah ED. Systemic disease associations with disorders of gut-brain interaction and gastrointestinal transit: a review. Clin Exp Gastroenterol. 2021;14:249. doi:10.2147/CEG. S283685
2. McElhanon BO, McCracken C, Karpen S, Sharp WG. Gastrointestinal symptoms in autism spectrum disorder: a meta-analysis. Pediatrics. 2014;133(5):872-883. doi:10.1542/ peds.2013-3995

3. Wasilewska J, Klukowski M. Gastrointestinal symptoms and autism spectrum disorder: links and risks-a possible new overlap syndrome. Pediatric Health Med Ther. 2015;6:153. doi:10.2147/PHMT.S85717

4. Afzal N, Murch S, Thirrupathy K, Berger L, Fagbemi A, Heuschkel R. Constipation with acquired megarectum in children with autism. Pediatrics. 2003;112(4):939-942. doi:10.1542/ peds.112.4.939

5. Buie T, Fuchs GJ, Furuta GT, et al. Recommendations for evaluation and treatment of common gastrointestinal problems in children with ASDs. Pediatrics. 2010;125(Supplement 1):S19-29. doi:10.1542/ peds.2009-1878D

Dove Medical Press encourages responsible, free and frank academic debate. The content of the Clinical and Experimental Gastroenterology 'letters to the editor' section does not necessarily represent the views of Dove Medical Press, its officers, agents, employees, related entities or the Clinical and Experimental Gastroenterology editors. While all reasonable steps have been taken to confirm the content of each letter, Dove Medical Press accepts no liability in respect of the content of any letter, nor is it responsible for the content and accuracy of any letter to the editor.

\section{Publish your work in this journal}

Clinical and Experimental Gastroenterology is an international, peerreviewed, open access, online journal publishing original research, reports, editorials, reviews and commentaries on all aspects of gastroenterology in the clinic and laboratory. This journal is indexed on American Chemical Society's Chemical Abstracts Service (CAS).
The manuscript management system is completely online and includes a very quick and fair peer-review system, which is all easy to use. Visit http://www.dovepress.com/testimonials.php to read real quotes from published authors. 